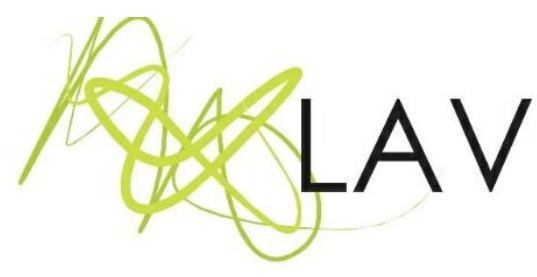

\title{
As crianças são artistas natas? Reflexões sobre a atividade criadora e as artes visuais na Educação Básica
}

Are children natural-born artists? Reflections on creative activity and visual arts in Basic Education

\author{
Vinícius Stein \\ Universidade Estadual de Maringá \\ Marta Chavesii \\ Universidade Estadual de Maringá
}

\section{Resumo}

Este artigo objetiva identificar o conceito de atividade criadora em pesquisas da Teoria Histórico-Cultural e suas implicações para o ensino de artes visuais na infância. Mediante pesquisa bibliográfica, apresenta-se o conceito de atividade criadora, considerando a relação dialética entre criação e reprodução, a partir da análise de frases sobre 'crianças', 'imaginação' e 'arte' comumente ouvidas em instituições de Educação Básica. Ao longo desta investigação, contrapõe-se concepções naturalizantes e sobrenaturais relacionadas à atividade criadora. Por fim, conclui-se que o desenvolvimento da criação está relacionado à apropriação de conhecimentos e habilidades desenvolvidos pela humanidade, pois a reprodução, no âmbito individual, daquilo que foi criado e compartilhado socialmente, representa a formação da base que possibilitará o desenvolvimento de novas criações.

Palavras-Chave: infância, teoria histórico-cultural, artes visuais.

\begin{abstract}
The present article aims at identifying the concept of creative activity in historical-cultural theory research and its implications for the teaching of visual arts during childhood. By means of bibliographic research, the concept of creative activity is presented, considering the dialectical relationship between creation and reproduction and, based on analyses of expressions about 'children', 'imagination' and 'art' commonly heard in basic education institutions. The present investigation contrasts naturalizing and supernatural conceptions related to creative activity and concludes that the development of creation is related to appropriation of knowledge and skills developed by humanity, because the reproduction, in the individual scope, of what was created and is socially shared, represents the formation base that will enable the development of new creations.
\end{abstract}

Keywords: childhood, historical-cultural theory, visual arts. 


\section{Considerações iniciais}

A frase tomada como provocação no título deste artigo, As crianças são artistas natas?, é comumente enunciada de modo afirmativo no senso comum. Propomos problematizar esta assertiva que, por vezes, também é reproduzida em espaços educativos, como nas instituições de Educação Básica ${ }^{1}$. Em iniciativas para a formação de professoras e professores para o ensino de arte na infância, costumamos solicitar que escrevam frases comumente ouvidas nos centros de educação infantil e em escolas nas quais trabalham, relacionando as palavras 'crianças', 'imaginação' e 'arte'. Além daquela expressa no título, recolhemos afirmações como 'Algumas crianças já nascem com dom para a arte'; 'As crianças têm a imaginação fértil'; 'O adulto pode tolher a imaginação da criança'; e 'Crianças, façam um desenho livre usando sua imaginação'.

Realizamos essa ação para convidar as professoras e professores à reflexão sobre as concepções acerca da atividade criadora comuns nos espaços educativos. A partir dos enunciados apresentados, realizamos estudos teóricos considerando que a compreensão conceitual sobre a imaginação e os processos de criação pode contribuir para a análise das propostas educativas com artes visuais realizadas na Educação Básica.

Diante disto, neste texto, atentamo-nos ao conceito de atividade criadora a partir de pesquisas da Teoria Histórico-Cultural. A origem das investigações relativas a esse referencial teórico-metodológico está relacionada com a trajetória intelectual de Lev Semionovitch Vigotski (1896-1934), Alexander Romanovitch Luria (1902-1977) e Alexei Nikolaevitch Leontiev (1903-1979). Suas pesquisas têm sido estudadas por profissionais das áreas da educação e da psicologia, pois contribuem para a compreensão sobre o desenvolvimento e a aprendizagem na infância.

Quando iniciamos a investigação que propiciou os resultados apresentados a seguir, interessava-nos identificar o conceito de atividade criadora nas pesquisas da Teoria Histórico-Cultural e suas implicações para o ensino de artes visuais na infância. Ao eleger a atividade criadora como objeto de pesquisa, reconhecemos que o termo usualmente utilizado nas escolas para se reportar à criação é 'criatividade', entretanto verificamos que essa palavra, como conceito, é pouco utilizada por Vigotski e pesquisadores vinculados à

\footnotetext{
${ }^{1}$ Segundo a lei que estabelece as diretrizes e bases da educação nacional (BRASIL, 1996), a educação escolar no país compõe-se de: I - educação básica, formada pela educação infantil, ensino fundamental e ensino médio; e II - educação superior (Art. 21). A educação infantil é realizada em creches e pré-escolas, com crianças de até cinco anos de idade (Art. 29). O ensino fundamental tem duração de nove anos, iniciando-se aos seis anos de idade (Art. 32) e, por fim, o ensino médio, possui duração mínima de três anos (Art. 35). O ensino da arte é garantido como componente curricular obrigatório da educação básica (Cf. §2० Art. 26). Neste texto, consideramos particularmente os espaços educativos organizados para as crianças, ou seja, aqueles voltados para pessoas com até 12 anos, como preconiza o Estatuto da Criança e do Adolescente (BRASIL, 1990).
} 
sua produção intelectual. Conforme explicou Prestes (2012), de modo geral, as pesquisas da Teoria Histórico-Cultural não versam sobre a criatividade em si, isto é, como uma qualidade própria do indivíduo, mas tratam da atividade criadora, ou seja, dos processos pelos quais a criação é realizada. Por essa razão, optamos pela expressão atividade criadora entendendo que denota um conceito no conjunto teórico-metodológico pesquisado.

Conforme demonstramos a seguir, o conceito de atividade criadora está diretamente relacionado ao de imaginação. Assim, tendo elegido as produções da Teoria Histórico-Cultural como referência principal para fundamentação de nosso trabalho e o delineamento bibliográfico (GIL, 2002) como metodologia de pesquisa, estabelecemos como fontes primárias as produções de autores implicados na criação, estabelecimento e consolidação das bases teórico-metodológicas desse referencial (IGNATIEV, 1969; PETROVSKY, 2017; VIGOTSKI, 2003, 2018a, 2018b), bem como pesquisadores contemporâneos, cujas pesquisas contribuíram para o objetivo de nossa investigação (CHAVES, 2011，2014，2020; PRESTES，2012; SACCOMANI，2016; SANTANA， 2016; TOASSA, 2004).

Na primeira parte deste artigo, caracterizamos o conceito de atividade criadora a partir de pesquisas da Teoria Histórico-Cultural. Na segunda, analisamos as frases sobre 'crianças', 'imaginação' e 'arte' citadas anteriormente nesta introdução, confrontando-as ao conceito de atividade criadora a reflexões desenvolvidas a partir do referido referencial teórico-metodológico. Por fim, demonstramos as implicações dos conceitos e análises apresentados para o ensino de artes visuais na infância.

\section{A atividade criadora: Concepção Histórico-Cultural dos processos de criação}

Consideramos o livro Imaginação e criação na infância, de Vigotski (2018a), uma obra fundamental para a compreensão do conceito de atividade criadora. Nele, o autor compreende a atividade criadora como "[...] aquela em que se cria algo novo" (VIGOTSKI, 2018a, p. 13, grifo no original). Em suas aulas sobre a pedologia² (VIGOTSKI, 2018b) tratou detalhadamente sobre o significado do 'novo' no desenvolvimento infantil. Segundo o autor, a própria definição de desenvolvimento está relacionada à constituição de uma característica nova. Afirmou que o 'novo' "[...] surge necessária e regularmente do

\footnotetext{
2 Vigotski (2018a) definiu a pedologia como a ciência do desenvolvimento da criança. Consideramos que o livro A pedologia histórico-cultural de Vigotski (SANTANA, 2016) apresenta contribuições significativas para a compreensão sobre as origens e marcos da ciência pedológica e as especificidades expostas por Vigotski em relação aos objetivos e métodos dessa área.
} 
curso precedente do desenvolvimento [...]" (VIGOTSKI, 2018b, p. 37, grifo no original) e, com isso, propôs que mesmo quando as origens que influenciam o aparecimento de dada qualidade nova não sejam evidentes, ainda assim o surgimento dessa nova qualidade só é possível em função de inúmeros fatores que precederam seu desenvolvimento.

Compreendemos, portanto, que a definição de 'algo novo' exige o reconhecimento do percurso que proporcionou a novidade em questão. No que tange à análise sobre a atividade criadora das crianças que frequentam as instituições de Educação Básica, consiste, por um lado, no reconhecimento da trajetória de vida do indivíduo criador (isto é, as experiências anteriores de cada criança em particular) e, por outro, do conjunto de conhecimentos produzidos coletivamente e cristalizado em diferentes formas pela humanidade ao longo do tempo (ou seja, as experiências acumuladas historicamente pelo gênero humano, como os conhecimentos sobre as artes visuais, por exemplo).

Há, portanto, uma relação dialética entre individual e coletivo que qualifica a novidade proporcionada pela atividade criadora. Uma criança que segura um pincel e cria formas com tinta sobre uma tela pela primeira vez, por exemplo, realiza um gesto novo, pois até então não havia realizado esse movimento por si mesma. Ocorre que o valor da novidade é parcial, pois é novo apenas na experiência da criança e em seu processo de desenvolvimento singular, mas não apresenta inovação significativa quando comparada ao conjunto de experiências humanas criadas coletivamente, pois esta ação já vem sendo realizada por inúmeras pessoas ao longo do tempo.

Assim, avaliamos que a atividade da criança, embora seja criadora do ponto de vista singular, deva ser valorizada pelo seu caráter 'reconstituidor' ou 'reprodutor', pois ainda que seja um ato novo em sua trajetória, essencialmente está reproduzindo ou reconstituindo um gesto que vem sendo realizado há muito tempo por diferentes sujeitos. Tratamos sobre isto a seguir.

\section{A atividade reconstituidora ou reprodutora: as bases para a criação}

Ao tratarmos da atividade 'reconstituidora' ou 'reprodutora', reportamo-nos às ações diretamente relacionadas à memória. Sua essencialidade consiste no ato de "[...] reproduzir ou repetir meios de conduta anteriormente criados e elaborados ou ressuscitar marcas de impressões precedentes" (VIGOTSKI, 2018a, p. 13). Sua característica fundamental é a reconstituição das experiências no esforço de aproximá-las maximamente

Revista Digital do LAV - Santa Maria - vol. 14, n. 2, p. 30 - 41 - mai./ago. 2021 ISSN 1983 - 7348 http://dx.doi.org/10.5902/1983734865220 
a um determinado padrão, isto é, à reprodução de uma situação percebida, compreendida e que tomou lugar na consciência do indivíduo (PETROVSKY, 2017).

Recuperando o exemplo exposto, entendemos que uma criança que segura um pincel e desenha com tinta sobre uma tela é capaz de realizar esse movimento com intencionalidade e consciência de seu gesto após tê-lo repetido inúmeras vezes. A maneira como segura o pincel, a quantidade de tinta que deixa nas cerdas e as formas que registra na tela são indícios das experiências que a criança teve anteriormente. Sendo capaz de segurar o pincel, aplicar tinta sobre o instrumento e transferi-la para um suporte poderá, mediante novas experimentações e ensino, aprender diferentes técnicas de pintura e, nesse processo, após numerosas tentativas, será capaz de realizar composições tecnicamente e conceitualmente mais complexas. Com isso, evidenciamos que as experiências compartilhadas socialmente podem proporcionar o desenvolvimento da memória das crianças, pois a apropriação de conhecimentos relacionados à pintura (sejam de caráter técnico, estético ou histórico, por exemplo) poderá contribuir para o desenvolvimento infantil.

Fisiologicamente, essa possibilidade está associada à plasticidade cerebral. A plasticidade consiste na capacidade de qualquer matéria receber modificações em sua estrutura, em conservar as marcas dessa modificação e apresentar predisposição para repetir as modificações realizadas. É, em síntese, "[...] a propriedade de uma substância que permite que ela seja alterada e conserve as marcas dessa alteração" (VIGOTSKI, 2018a, p. 14). Para Vigotski (2003), a substância nervosa humana é a mais plástica de todas as matérias existentes na natureza, pois "[...] pode desenvolver, como nenhuma outra, a capacidade para as mudanças, para a acumulação de suas marcas e para a predisposição, que constituem a base da memória" (VIGOTSKI, 2003, p. 144).

Assim, o cérebro humano apresenta a base fisiológica para a memória em função de sua grande plasticidade (VIGOTSKI, 2018a), mas a constituição cerebral por si mesma é insuficiente para o desenvolvimento dessa função psicológica superior. A memória existe em função da estrutura cerebral, mas, como destacamos, é determinada pelas experiências que deixam marcas no cérebro.

Ocorre que, se por um lado as crianças reproduzem os modelos que têm à sua disposição e por vezes reconstituem formas, gestos e palavras semelhantes àqueles próprios das pessoas com as quais convivem e aos conhecimentos que tiveram acesso, por outro, também surpreendem os adultos ao seu redor por apresentarem comportamentos, atitudes e ideias aparentemente inusitados e inovadores, que à primeira vista não coincidem com as experiências já vivenciadas por elas. Quando contam histórias 
fantásticas, inventam explicações incomuns e fazem desenhos com figuras que não existem na realidade objetiva, por exemplo, estão cristalizando suas criações. Tratamos disto a seguir.

\section{A atividade criadora ou combinatória: a constituição da criação}

Além do caráter 'reconstituidor' ou 'reprodutor', a atividade humana pode ser manifestada de modo 'combinatório' ou 'criador'. Nas palavras de Vigotski (2018a):

Toda a atividade do homem que tem como resultado a criação de novas imagens ou ações, e não a reprodução de impressões ou ações anteriores da sua experiência, pertence a esse segundo gênero de comportamento criador ou combinatório (VIGOTSKI, 2018a, p. 15).

Nesse sentido, os humanos não apenas conservam e reproduzem suas experiências anteriores, mas as reelaboram, dando origem ao que até então não fora criado (VIGOTSKI, 2018a). A função psicológica superior, cuja característica principal refere-se à combinação dos elementos extraídos das experiências dos sujeitos, é denominada por Vigotski (2003, 2018a), Ignatiev (1969) e Petrovsky (2017) como 'imaginação' ou 'fantasia'.

Imaginar é, portanto, dispor da "[...] capacidade de criar novas imagens sensoriais ou racionais na consciência humana, com o intuito de transformar as impressões recebidas pela realidade" (PETROVSKY, 2017, p. 182). Desse modo, enquanto pela atividade reprodutora (a memória) há a conservação das representações motivadas pelas experiências vividas, pela atividade combinatória ou criadora (a imaginação) há a transformação dessas representações, gerando a criação de um arranjo verdadeiramente novo, nunca apresentado antes (PETROVSKY, 2017).

Essa constatação nos sugere que para desenvolver a criação é necessário ampliar as experiências do indivíduo criador, pois a imaginação será constituída pelos elementos por ele vivenciados. Com base nisso, na sequência, tratamos da dupla relação entre reprodução e criação no contexto da educação básica, analisando as frases apresentadas nas considerações iniciais deste artigo. 


\section{Artes visuais e criação infantil na educação básica: reflexões sobre afirmativas comuns}

$\mathrm{Na}$ introdução deste texto, já mencionamos que analisaremos as afirmativas ouvidas em instituições educativas que expressam concepções sobre 'crianças', 'imaginação' e 'arte', no tocante à concepção de criação proposta nas pesquisas da Teoria Histórico-Cultural.

Iniciamos pelas expressões 'Algumas crianças já nascem com dom para a arte' e 'As crianças são artistas natas'. Consideramos que ambas divergem dos pressupostos da Teoria Histórico-Cultural por atribuírem a atividade criadora a um princípio sobrenatural e biológico, respectivamente. No primeiro caso, predomina a crença de que as habilidades para as artes são um dom recebido de alguma divindade e, no segundo, uma condição hereditária. Ambas se opõem ao desenvolvimento da criação relacionada à arte, pois uma o restringe ao sobrenatural e outra exclusivamente à natureza.

Ao contrário, como descrevemos, a criação está diretamente relacionada às experiências do indivíduo criador. Dessa maneira, como o próprio Vigotski declarou, "[...] os dons também se transformam em tarefa da educação, embora na velha psicologia eles figurassem apenas como uma condição e um dado da educação" (VIGOTSKI, 2003, p. 239, grifos no original). No que tange aos aspectos hereditários, o autor discorreu detalhadamente acerca de sua influência no desenvolvimento infantil em sua aula intitulada $O$ estudo da hereditariedade e do meio na pedologia (VIGOTSKI, 2018b). Em sua perspectiva, para a compreensão e análise do desenvolvimento intelectual, as condições hereditárias não devem ser consideradas por si mesmas, mas na relação com as experiências vividas pelos sujeitos.

O autor já havia demonstrado em História do desenvolvimento das funções psíquicas superiores (VYGOTSKY, 2003) que o desenvolvimento psicológico parte dos condicionamentos de natureza biológica e hereditária que determinam quais serão os processos próprios da primeira fase da vida (as funções elementares), mas são gradativamente transformados pelas influências recebidas pelo bebê no contato com a vida cultural que se estabelece ao seu redor (proporcionando o desenvolvimento de funções psíquicas superiores). Com isso, reafirmou o caráter dialético de seu método de investigação, reconhecendo a dupla relação entre hereditariedade e meio, mas atribuindoIhes condições diferenciadas no curso do desenvolvimento. E, além da naturalização das funções psicológicas humanas, posicionou-se contrário à idealização da infância como período de maior atividade criadora. 
Para ilustrar isso, retomamos a afirmação 'As crianças têm a imaginação fértil'. Essa frase é comumente utilizada para valorizar uma suposta imaginação própria das crianças que parece diminuir com o passar do tempo. Nessa lógica, 'imaginar como as crianças' é um ideal a ser atingido pelos adultos. Ao contrariar essa posição, as pesquisas revelaram que, embora a criação seja possibilitada pela constituição fisiológica humana (e, assim, a plasticidade cerebral infantil poderia ser considerada um terreno fértil) a realização da atividade criadora está subordinada às experiências do indivíduo. Diante disso, concordamos que a infância é um período de fertilidade devido à alta plasticidade ${ }^{3}$ cerebral possível nessa etapa da vida humana, mas frisamos que a possibilidade de imaginar está relacionada a outros fatores e, sobretudo, aos conhecimentos apropriados pelos indivíduos. Nesse âmbito, é fundamental o papel do meio no desenvolvimento infantil, como salientou Vigotski na aula intitulada O problema do meio na pedologia (VIGOTSKI, 2018b).

Consideramos ainda outra afirmativa: 'O adulto pode tolher a imaginação da criança'. Nesse caso, o verbo utilizado para caracterizar a ação do adulto denota impedimento, corte, obstáculo, trava e coerção. Está implícita na frase a concepção de que algumas funções psicológicas humanas (como a imaginação neste caso) são, em sua origem, herdadas biologicamente e que se desenvolvem naturalmente no decorrer da vida, se nenhum adulto interferir (tolher) nesse processo espontâneo. Discordamos dessa concepção, pois, como evidenciamos anteriormente, a Teoria Histórico-Cultural opõe-se a uma concepção naturalizante do desenvolvimento infantil. Além disso, a frase em análise também é utilizada para a defesa da manutenção e preservação de uma forma de criar própria das crianças. Nesse sentido, conforme Saccomani (2016), é recorrente a ideia de que o professor deve respeitar as necessidades e inclinações espontâneas dos alunos e adaptar a escola a elas. Em oposição a essa assertiva, a autora criticou a ideia de que "[...] a criatividade é da ordem do espontâneo e do individual e, portanto, qualquer intervenção sistematizada interferiria no desenvolvimento dessa capacidade humana" (SACCOMANI, 2016, p.15).

\footnotetext{
${ }^{3}$ Pesquisas da neurociência comprovaram a relação entre plasticidade e experiência no desenvolvimento humano. Hermida, Segretin e Lipina (2017) analisam, com base em uma revisão de estudos da neurociência, o postulado de que os três primeiros anos são "[...] como uma 'janela' no desenvolvimento, um período limitado e crucial para a formação de certas funções cerebrais e comportamentais" (HERMIDA; SEGRETIN; LIPINA, 2017, p. 71). Os autores refutaram essa concepção e demonstraram que esses anos são importantes, mas não são críticos, ou seja, não representam janelas de tempo durante as quais as experiências geram mudanças irreversíveis no cérebro. Afirmam que este é um período sensível, isto é, "[...] um tempo muito importante para o desenvolvimento de uma função [...], mas que não compreende um tempo tão limitado como o do período crítico, nem irreversibilidade após a finalização do período" (HERMIDA; SEGRETIN; LIPINA, 2017, p. 76). Com isso, reafirmam que a plasticidade cerebral dura a vida toda, o que garante a possibilidade de aprendizagem em diferentes etapas da vida.
}

Revista Digital do LAV - Santa Maria - vol. 14, n. 2, p. 30 - 41 - mai./ago. 2021 ISSN 1983 - 7348 
Assim, consideramos que o adulto pode interferir de modo inadequado na criação infantil, mas essa interferência, contrariamente à ideia comum, ocorre justamente quando as professoras e professores prescindem da responsabilidade de ampliar as referências das crianças, apresentando-Ihes novas formas de desenhar, pintar, modelar, compor e analisar imagens, por exemplo. É o que por vezes ocorre quando Ihes é proposto: 'Façam um desenho livre usando sua imaginação'. Constatamos que ao dizer isso, geralmente os docentes disponibilizam papéis e lápis ou gizes às crianças e deixam-nas desenhando espontaneamente. Em nossa avaliação, essa proposta de maneira isolada, isto é, sem uma preparação prévia e intencional por parte das professoras e professores, não contribui efetivamente para o desenvolvimento da imaginação e o aprimoramento dos processos de criação na infância. Embora possibilite às crianças cristalizar algumas ideias em forma de desenho, não corresponde à ideia de liberdade ${ }^{4}$ de criação. Consideramos que a atitude docente ao proporcionar a criação sem limites (ou 'livre') deixa as crianças subordinadas às suas próprias limitações, ou seja, àquilo que elas já conhecem e que representa seu nível de desenvolvimento atual ${ }^{5}$.

Entendemos que a chamada natureza infantil, ao contrário do que se compreende por meio do enunciado analisado, não é decorrente de um amadurecimento biológico espontâneo, mas desenvolvida a partir do conjunto de referências culturais no qual a criança está submetida. Sua gênese e seu caráter não são naturais, mas sim sociais. Desse modo, as referências culturais estão sempre presentes nas ações humanas e, por conseguinte, não cabe contrapô-las à liberdade de criação e à espontaneidade (OSTROWER, 2001). Essas referências expressam os limites da experiência de cada indivíduo, e o reconhecimento desses limites potencializa a ação criadora. Como salientou Ostrower (2001), "[...] a própria aceitação de limites [...] é o que nos propõe o real sentido da liberdade no criar" (OSTROWER, 2001, p. 160, grifos no original).

Nessa direção, pautar a atividade criadora na Educação Básica com o objetivo de promover o desenvolvimento da imaginação impõe-se como um desafio teóricometodológico a ser enfrentado pelos profissionais da educação, conforme propôs Chaves

\footnotetext{
${ }^{4}$ Sobre o conceito de liberdade em Vigotski recomendamos o texto de Toassa (2004).

${ }^{5}$ Prestes (2012) discutiu sobre o significado da expressão zona de desenvolvimento atual como conceito na obra de Vigotski e suas traduções no Brasil. Segundo a autora Vigotski utilizou tanto a expressão 'zona de desenvolvimento atual' quanto 'desenvolvimento real' para tratar sobre o nível efetivo de desenvolvimento da criança. Esse conceito está diretamente relacionado ao de 'zona blijaichego razvitia', traduzido no Brasil como zona de desenvolvimento proximal, próximo ou imediato. Para Prestes (2012) a tradução adequada ao conceito expresso por Vigotski é 'zona de desenvolvimento iminente'. Conforme explicou "[...] sua característica essencial é a das possibilidades de desenvolvimento, mais do que do imediatismo e da obrigatoriedade de ocorrência, pois se a criança não tiver a possibilidade de contar com a colaboração de outra pessoa em determinados períodos de sua vida, poderá não amadurecer certas funções intelectuais e, mesmo tendo essa pessoa, isso não garante, por si só, o seu amadurecimento" (PRESTES, 2012, p.205).
} 
(2011; 2014; 2020). Para a autora, as professoras e professores devem ser instrumentalizados para desenvolver propostas nas quais reconheçam as necessidades dos escolares e os valores culturais próprios do local onde estão inseridos e, simultaneamente, ampliem esses limites possibilitando experiências para além do que está disponível na realidade imediata.

\section{Considerações finais}

Compreendemos o conceito de atividade criadora na relação dialética entre criação e reprodução. Conforme demonstramos, a criação do novo resulta de um processo de desenvolvimento que pode ser identificado em duas dimensões, tanto na trajetória de vida do indivíduo criador (quando a criação é nova para quem cria) quanto no conjunto de conhecimentos produzidos coletivamente e cristalizado em diferentes formas pela humanidade ao longo do tempo (quando a criação representa o avanço de uma área do conhecimento).

Nessa perspectiva, os processos de criação são compreendidos na relação dialética entre reproduzir e criar, pois enquanto a atividade reprodutora, ligada à memória, permite a conservação das experiências vivenciadas pelos sujeitos, a atividade combinatória ou criadora, ligada à imaginação, possibilita a transformação dessas representações, dando origem a algo novo. Ocorre que, conforme exemplificamos, essa concepção diverge de afirmativas relativas às 'crianças', 'imaginação' e 'arte' comuns no ideário pedagógico, que denotam explicações naturalizantes e sobrenaturais à atividade criadora.

Consideramos que o desenvolvimento da criação está relacionado à apropriação de conhecimentos e habilidades desenvolvidos pela humanidade, pois a reprodução, no âmbito individual, daquilo que foi criado e compartilhado socialmente, representa a formação da base que possibilitará o desenvolvimento de novas criações.

Diante disso, consideramos que, em proposições educativas com artes visuais nas instituições educativas, as professoras e professores podem organizar o ensino priorizando o desenvolvimento específico da memória ou da imaginação por meio de propostas que valorizem a atividade de caráter reprodutor e criador, respectivamente. Parece-nos adequado que exemplos das produções artísticas sejam expostos, vistos, discutidos, analisados, contextualizados, imitados e possam servir como referência para a atividade criadora na infância. 


\section{Referências}

BRASIL. Lei no 8.069, de 13 de julho de 1990. Dispõe sobre o Estatuto da Criança e do Adolescente e dá outras providências. 1990. Disponível em: <http://www.planalto.gov.br/ccivil_03/leis//8069.htm>. Acesso em: 7 abr. 2021.

BRASIL. Lei no 9.394, de 20 de dezembro de 1996. Estabelece as diretrizes e bases da educação nacional. $1996 . \quad$ Disponível em: <http://www.planalto.gov.br/ccivil_03/leis/19394.htm>. Acesso em: 7 abr. 2021.

CHAVES, M. Enlaces da Teoria Histórico-Cultural com a Literatura Infantil. In: CHAVES, M. (org.). Práticas pedagógicas e literatura infantil. 1. ed. v. 1. Maringá: Eduem. 2011.

CHAVES, M. Formação contínua de professores e a teoria histórico-cultural na educação infantil. Fractal: Revista de Psicologia, v. 32, n. esp, p. 227-232, 1 jul. 2020. Disponível em: <https://periodicos.uff.br/fractal/article/view/41036>. Acesso em: 7 abr. 2021.

CHAVES, M. Leontiev e Blagonadezhina: estudos e reflexões para considerar a organização do tempo e do espaço na Educação Infantil. Teoria e Prática da Educação, v. 17, p. 8191, $2014 . \quad$ Disponível em: <https://periodicos.uem.br/ojs/index.php/TeorPratEduc/article/view/28210>. Acesso em: 7 abr. 2021.

GIL, A. C. Como elaborar projetos de pesquisa. São Paulo: Atlas. 2002.

HERMIDA, J.; SEGRETIN, S.; LIPINA, S. Quem disse que tudo está perdido? Compreendendo melhor as janelas de oportunidade. In: ZEGGIO, L.; EKUNI, R.; BUENO, O. F. A. (org). Caçadores de neuromitos: desvendando s mistérios do nosso cérebro. Florianópolis: IBIES. 2017.

IGNATIEV, E. I. La imaginación. In: SMIRNOV, A. A.; LEONTIEV, A. N.; RUBINSHTEIN, S. L.; TIEPLOV, B. M. Psicología. Tradução de Florencio Villa Landa. 3. ed. México: Editorial Grijalbo. 1969.

OSTROWER, F. Criatividade e processos de criação. 15. ed. Petrópolis, RJ: Vozes. 2001.

PETROVSKY, A. V. A imaginação. Tradução de Maria Aparecida Mello e Douglas Aparecido de Campos. Revisão de Ruben de Oliveira Nascimento. In: LONGAREZI, A. M.; PUENTES, R. V. (org.). Ensino desenvolvimental: antologia. Livro I. Tradução de Ademir Damazio et al. Uberlândia, MG: EDUFU. 2017 (Coleção Biblioteca Psicopedagógica e Didática. Série ensino desenvolvimental, v. 4).

PRESTES, Z. R. Quando não é quase a mesma coisa. Tradução de Lev Semionovitch Vigotski no Brasil. 1. ed. Campinas, SP: Autores Associados. 2012.

SACCOMANI, M. C. da S. A criatividade na arte e na educação escolar: uma contribuição à pedagogia histórico-crítica à luz de Georg Lukács e Lev Vigotski. Campinas, São Paulo. Autores Associados. 2016. (Educação contemporânea).

SANTANA, C. da C. G. A Pedologia Histórico-Cultural de Vigotski. 1. ed. São Carlos: Pedro \& João Editores. 2016. 
TOASSA, G. Conceito de liberdade em Vigotski. Psicologia: Ciência e Profissão (Impresso), Brasília, v. 24, n.3, p. 2-11. 2004. Disponível em: <http://pepsic.bvsalud.org/scielo.php?pid=S1414-98932004000300002\&script=sci_ abstract>. Acesso em: 7 abr. 2021.

VIGOTSKI, L. S. Educação Estética. In: VIGOTSKI, L. S. Psicologia pedagógica: edição comentada. Tradução de Claudia Schilling. Porto Alegre: Artmed, 2003.

VIGOTSKI, L. S. Imaginação e criação na infância: ensaio psicológico. Tradução de Zoia Prestes e Elizabeth Tunes. 1. ed. São Paulo: Expressão Popular, 2018a.

VIGOTSKI, L. S. Sete aulas de L.S. Vigotski sobre os fundamentos da pedologia; organização de Zoia Prestes, Elizabeth Tunes; tradução de Cláudia da Costa Guimarães Santana. 1. ed. Rio de Janeiro: EPapers, 2018b.

VYGOTSKY, L. S. Historia del desarrollo de las funciones psíquicas superiores. In: VYGOTSKY, L. S. Obras Escogidas. Tomo III. Problemas del desarollo de la psique. Tradução de Lydia Kuper. 2. ed. Madrid: Visor Dis. 2003.

\footnotetext{
' Possui graduação em Arte-Educação pela Universidade Estadual do Centro-Oeste (2011). Especialização em Teoria Histórico-Cultural pelo departamento de Psicologia da Universidade Estadual de Maringá (2014). Mestrado em Educação pelo Programa de PósGraduação em Educação da Universidade Estadual de Maringá (2014). Doutorado em Educação pelo Programa de Pós-Graduação em Educação da Universidade Estadual de Maringá (2019). Recebeu bolsa da Fundación Carolina para pesquisa na Universidad de Huelva - Espanha (2018). Integra o Grupo de Pesquisa e Estudos em Educação Infantil (GEEI) e o Grupo de Pesquisa em Arte, Educação e Imagem (ARTEI). Pesquisa sobre ensino das artes visuais na educação escolar e educação estética.

ii Possui graduação em Pedagogia pela Universidade Estadual de Maringá (1993). Mestrado em Educação pela Universidade Estadual de Maringá (2000). Doutorado em Educação pela Universidade Federal do Paraná (2008). Pós-Doutorado junto ao Departamento de Psicologia da Educação, na Faculdade de Ciências e Letras do Campus de Araraquara Unesp (2011). É professora associada do Departamento de Teoria e Prática da Educação da Universidade Estadual de Maringá e líder do Grupo de Pesquisa e Estudos em Educação Infantil (GEEI). Tem experiência na área de Educação, com ênfase em História da Educação, atuando principalmente nos seguintes temas: Formação de professores, Educação Infantil, Teoria Histórico-Cultural, Literatura Infantil, Arte e Intervenções Pedagógicas.
}

Como citar esse artigo:

STEIN, Vinícius; CHAVES, Marta. As crianças são artistas natas? Reflexões sobre a atividade criadora e as artes visuais na Educação Básica. Revista Digital do LAV, Santa Maria: UFSM, v. 14, n. 2, p. 30-41, mai./ago. 2021. 